\title{
Prevalence and associated factors of sarcopenia in Singaporean adults - the Yishun Study
}

\section{Benedict Wei Jun Pang ( $\sim$ L3enanapang@gmail.com )}

Geriatric Education and Research Institute (GERI)

Shiou Liang Wee ( $\square$ ShiouLiang.Wee@SingaporeTech.edu.sg )

Singapore Institute of Technology https://orcid.org/0000-0002-7853-4112

\section{Lay Khoon Lau}

Geriatric Education and Research Institute (GERI)

Khalid Abdul Jabbar

Geriatric Education and Research Institute (GERI)

Wei Ting Seah

Geriatric Education and Research Institute (GERI)

Daniella Hui Min $\mathbf{~} g$

Geriatric Education and Research Institute (GERI)

Queenie Lin Ling Tan

Geriatric Education and Research Institute (GERI)

\section{Kenneth Kexun Chen}

Geriatric Education and Research Institute (GERI)

\section{Mallya Ullal Jagadish}

Geriatric Education and Research Institute (GERI)

\section{Tze Pin Ng}

National University of Singapore

\section{Research Article}

Keywords: muscle strength, sarcopenia, muscle mass, Singapore, prevalence

Posted Date: May 14th, 2020

DOl: https://doi.org/10.21203/rs.3.rs-28685/v1

License: (a) (i) This work is licensed under a Creative Commons Attribution 4.0 International License. Read Full License 
Version of Record: A version of this preprint was published at Journal of the American Medical Directors Association on April 1st, 2021. See the published version at https://doi.org/10.1016/j.jamda.2020.05.029. 


\section{Abstract}

Objectives: To describe the normative values of sarcopenia among community-dwelling adults $(\geq 21)$, compare the prevalence of sarcopenia using AWGS2014, AWGS2019 and EWGSOP2 guidelines, and identify factors associated with sarcopenia.

Design: Participants were recruited through random sampling. Sarcopenia assessments were performed using a DXA scan (muscle mass), handgrip test (muscle strength) and usual walking test (physical performance). Questionnaires were administered to evaluate lifestyle and cognition.

Setting and Participants: 542 community-dwelling Singaporeans were recruited (21-90 years old, 57.9\% women).

Methods: We assessed anthropometry, body composition, and questionnaire-based physical and cognitive factors, and estimated sarcopenia prevalence according to the AWGS2014, AWGS2019 and EWGSOP2 recommendations, and examined associations using logistic regression.

Results: According to AWGS2019, the Singapore population-adjusted sarcopenia prevalence was $13.6 \%$ (men 13.0\%; women 14.2\%) overall, and 32.2\% (men 33.7\%, women $30.9 \%$ ) in those aged 60 and above. The cut-offs derived from young adult reference group for low ALMI is $5.28 \mathrm{~kg} / \mathrm{m}^{2}$ for men and 3.69 $\mathrm{kg} / \mathrm{m}^{2}$ for women (lower than AWGS recommended cut-off); for GS it is $0.82 \mathrm{~m} / \mathrm{s}$, (AWGS2019 recommended cut-off $1.0 \mathrm{~m} / \mathrm{s}$, AWGS2014 cut-off was $0.8 \mathrm{~m} / \mathrm{s}$ ); for HGS, it is $27.9 \mathrm{~kg} / \mathrm{m}^{2}$ for men, and $16.7 \mathrm{~kg} / \mathrm{m}^{2}$ for women (close to AWGS2019 recommendation). Age, gender, marital status, alcoholism, physical activity, BMl, waist circumference and global cognition were associated with sarcopenia $(p<.05)$.

Conclusions and Implications: This is the first study to provide reference values of muscle mass, strength and gait speed across the adult lifespan of Singaporeans. Using AWGS2019 criteria, sarcopenia is prominent in older age (32.2\% in $\geq 60$ years old); but it is already non-trivial $(6.9 \%)$ among young and middle-aged persons. Multi-domain lifestyle modifications addressing muscle strength, cognition and nutrition over the adult lifespan is important to delay the development of sarcopenia.

\section{Introduction}

Sarcopenia is an age-associated muscle disease characterised by the progressive loss of muscle mass, strength and function. 1 Given its associations with disability, falls, need for long-term care and mortality, 1,2 rising sarcopenia prevalence due to longer life expectancy constitutes a public health concern. Since the recent upsurge in sarcopenia research (2000), studies have reported widely-differing sarcopenia prevalence. To standardize its diagnosis and harmonize working definitions across studies, the European Working Group on Sarcopenia in Older People (EWGSOP) in 2010 published the first guidelines on sarcopenia classifications and diagnostic cut-offs.3 In 2018, it revised its classification to recognize that low muscle strength constitutes 'probable sarcopenia', low muscle mass confirms the diagnosis, and physical function determines the severity (EWGSOP2).1 
To address ethnic differences in body size and lifestyles, the Asian Working Group for Sarcopenia (AWGS) proposed its own diagnostic criteria for Asians in 2014 (AWGS2014).4 A 2016 review found widely-differing prevalence in Asian populations, and concluded that further revisions to cut-offs are required, while calling for more data from Asia.5 In 2019, the criteria was revised to recognize poor muscle strength and/or physical performance as 'possible sarcopenia', low muscle mass and poor muscle strength or physical performance as 'sarcopenia', while the presence of all three constitutes 'severe sarcopenia' (AWGS2019). 6 The cut-offs for slow gait speed were raised from 0.8 to $1.0 \mathrm{~m} / \mathrm{s}$ and low handgrip strength for men from 26 to $28 \mathrm{~kg}$. These changes are expected to inflate sarcopenia prevalence, 6 but to what extent is unknown.

In Singapore, a few small-sample studies have reported sarcopenia prevalence using different measurement instruments and sarcopenia domains on various population groups. Using the SARC-F questionnaire, a prevalence of $44.3 \%$ was reported for 115 outpatients ( $\geq 65$ years) attending specialist clinics.7 Among 186 community-dwelling older adults, 53.8\% had low muscle mass (DXA-ALM/Ht2) using EWGSOP cut-offs (Conference Abstract). 8 Amidst 387 type 2 diabetic older adults in primary care, $58 \%$ showed low muscle mass (bioimpedance estimated) and $28 \%$ had sarcopenia according to AWGS2014.9 A fourth study, using AWGS2014 guidelines, reported a low muscle mass (bioimpedance estimated) prevalence of $20.6 \%$ among 400 community-dwelling adults ( $\geq 65$ years). 10 These studies have several limitations. The SARC-F has low sensitivity in screening for sarcopenia.11 Compared to the dual-energy X-ray absorptiometry (DXA), the bioimpedance estimate is also less reliable in measuring muscle mass due to its dependence on assessment conditions. 4 To date, there is no data on sarcopenia prevalence, muscle mass and function based on gold standard measurements among Singaporeans in a representative community-dwelling sample that includes younger and older adults.

Studies suggest earlier onset and deterioration of muscle mass, strength and function attributed to physiological and neuromuscular changes, 1 sedentary lifestyles, 12 inadequate nutrition, 13 obesity 14 , neurocognitive decline 15 , and more recently, the emerging role of gut microbiome in muscle health.16 Studying the age-associated changes in muscle mass and function, development of sarcopenia across the lifespan and its associated factors in the multi-ethnic population of Singapore contributes important data towards a better understanding and definition of sarcopenia among Asians.

The aims of the present study are: (1) to describe the normative values of muscle mass, strength and function among community-dwelling adults in Singapore, (2) estimate sarcopenia prevalence using AWGS2014, AWGS2019 and EWGSOP2 guidelines, and (3) identify factors associated with AWGS2019 and EWGSOP2 sarcopenia.

\section{Methods}

Setting

Community-dwelling adults ( $\geq 21$ years) were recruited from a large north-eastern residential town of Yishun in Singapore, with residential population of 220,320 (50.6\% females), with $12.2 \%$ older adults 
( $\geq 65$ years).17 This is similar to the overall Singapore residential population of 4,026,210 $(51.1 \%$ females), with $14.4 \%$ older adults ( $\geq 65$ years). 17

\section{Participants}

Random sampling was employed to obtain a representative sample of approximately 300 male and 300 female participants, filling quotas of 20-40 participants in each sex- and age-group (10-year age-groups between 21-60; 5-year age-groups after 60). Conventionally, the sample size of 30 or greater per agegroup is sufficient for normative measures. 18 Between October 2017 and February 2019, using two-stage random sampling, $50 \%$ of all housing blocks were selected, and $20 \%$ of the units were approached for participant recruitment. Between March and November 2019, 50\% of all housing blocks were randomly selected and all units approached. Up to three eligible participants were recruited from each unit. Nonresponse units were re-contacted a second time at a different time of day on a later date. Older adults (>75 years) were additionally recruited through community sources and from a list of registered participants in four senior activity centres. Exclusion criteria were: individuals with disabilities, injuries, fractures or surgeries affecting function, neuromuscular, neurological and cognitive impairments, or more than five poorly-controlled comorbidities. Pregnant women or those planning for pregnancy were also excluded. Overall response rate was 39.0\%. Ethics approval was obtained from the National Healthcare Group DSRB (2017/00212). All respondents signed informed consent before participating in the study.

\section{Questionnaires}

Participants answered questionnaires pertaining to education level, housing type, living arrangement, marital status, smoking and alcoholism, a health and medical questionnaire indicating medical conditions and comorbidities, a mini nutritional assessment (MNA),19 a global physical activity questionnaire (GPAQ)20 and the LASA physical activity questionnaire. 21

\section{Anthropometry}

Body weight to the nearest $0.1 \mathrm{~kg}$ and height to nearest millimetre were measured using a digital balance and stadiometer (Seca, GmbH \& Co. KG, Hamburg, Germany). Waist and hip circumferences were measured using a non-elastic, flexible measuring tape around the navel and widest part of the hips respectively. Body mass index (BMI) was calculated as weight $(\mathrm{kg})$ divided by height $(\mathrm{m})$ squared.

\section{Cognitive Assessment}

Global cognition and cognitive domains including immediate and delayed memory, visuospatial, language and attention were assessed using the Repeatable Battery for the Assessment of Neuropsychological Status (RBANS).22

\section{Body Composition}


Bone mineral density and appendicular lean mass (ALM) were measured using DXA (Discovery WI, Hologic, Inc., Marlborough, USA). Appendicular lean mass index (ALMI) was calculated as ALM (kg) divided by height $(\mathrm{m})$ squared, where ALM equals to the sum of lean mass in the upper and lower limbs.

\section{Handgrip Strength}

Handgrip strength (HGS) was assessed using the Jamar Plus+ Digital Hand Dynamometer (Patterson Medical, Evergreen Boulevard, Cedarburg, USA). Seated with arms 90 degrees to the sides, two trials were taken per arm in an alternating fashion with $30 \mathrm{~s}$ of rest between trials. The highest reading was recorded.

\section{Gait Speed}

Usual gait speed (GS) was measured using the $6 \mathrm{~m}$ GAITRite Walkway (CIR Systems Inc., Sparta. New Jersey, USA) with a $2 \mathrm{~m}$ lead in and out phase. Three trials were taken. The average GS was recorded.

\section{Sarcopenia}

Sarcopenia was assessed using the AWGS20144, AWGS20195 and EWGSOP21 criteria. Poor physical function was defined as GS $<1.0 \mathrm{~m} / \mathrm{s}$ (AWGS2014 $\leq 0.8 \mathrm{~m} / \mathrm{s}$ ), low muscle mass as ALMI $<7.0$ and $<5.4$ $\mathrm{kg} / \mathrm{m} 2$, and muscle strength by HGS $<28 \mathrm{~kg}$ (AWGS2014 $<26 \mathrm{~kg}$ ) and $<18 \mathrm{~kg}$ for men and women respectively. AWGS2014 categorizes low muscle mass and poor muscle strength and/or physical function as 'sarcopenia'.4 AWGS2019 recognizes poor muscle strength and/or physical function as 'probable sarcopenia', while low muscle mass and poor muscle strength or physical performance constitutes 'sarcopenia confirmed'.5 EWGSOP2 recognizes low muscle strength as 'probable sarcopenia', with low muscle mass confirming the diagnosis.1 Presence of all three constitutes 'severe sarcopenia' in both AWGS2019 and EWGSOP2.1,5

\section{Statistical Analysis}

SPSS version 22 (Chicago, Illinois, USA) was used for analysis. Continuous variables were reported as mean (SD) and categorical variables as number (\%). Sample estimates of sarcopenia were extrapolated to the general population weights by age groups. Univariate and multivariable logistic regressions using backward stepwise selection (removal threshold: $p=.05$ ) were performed to examine factors associated with sarcopenia, without correction for multiple significance testing. No sarcopenia and sarcopenia probable were grouped as "no sarcopenia", and "sarcopenia" was defined as sarcopenia confirmed and severe sarcopenia. Statistical significance was set at $p<.05$.

\section{Results}

A total of 542 participants (57.9\% females) aged 21-90 years were recruited. Due to incomplete data from six participants, data from 536 participants were analysed. Of these, $81.7 \%$ were Chinese, $8.6 \%$ Malays, 
$6.9 \%$ Indians, and 2.8\% from other races. Mean age was 58.5 (18.8) years. The descriptive statistics are presented in Supplementary Table 1, S1.

The prevalence of sarcopenic phenotypes according to age-groups are presented in Table 1., and comparisons among the three different criteria (i.e., AWGS2014, AWGS2019 and EWGSOP2) shown in Figure 1. Overall population-adjusted prevalence of low muscle mass was $40.6 \%$. Using AWGS2014 guidelines, the prevalence of low muscle strength was $7.3 \%$ and slow gait speed $4.1 \%$. With AWGS2019, the prevalence of low muscle strength increased to $9.0 \%$ and slow gait speed to $24.0 \%$, while prevalence of 'probable sarcopenia' was $14.0 \%$, 'sarcopenia confirmed' $9.5 \%$ and 'severe sarcopenia' $4.1 \%$, compared to EWGSOP2's 1.8\% (probable), 3.1\% (confirmed) and 4.1\% (severe).

Overall sarcopenia prevalence according to AWGS2014 was 6.7\% (male 6.9\%; female 6.4\%) compared to AWGS2019's 13.6\% (male 13.0\%; female 14.2\%) and EWGSOP2's 7.1\% (male 9.1\%; female 5.3\%;

\section{Supplementary Table, S2.).}

\section{Study Norms}

The number of young adults sampled (21-40 years), mean age 30.5 (6.1) years, was $n=121$ (55.4\% females). Population-specific cut-offs, derived by subtracting two SD from the young reference mean,1,3 for GS is $0.82 \mathrm{~m} / \mathrm{s}$ (close to AWGS2014); for HGS, 27.9 and $16.7 \mathrm{~kg}$ (close to AWGS2019); and for ALMI, 5.28 and $3.69 \mathrm{~kg} / \mathrm{m} 2$ (lower than AGWS) for men and women respectively. Using these cut-offs, the prevalence of low muscle strength is $7.2 \%$ (overall) and $18.9 \%$ ( $\geq 60$ years), muscle mass $0.3 \%$ (overall) and $1.1 \%(\geq 60)$, and physical performance $4.9 \%$ (overall) and $11.9 \%(\geq 60)$.

\section{Factors associated with sarcopenia}

Table 3 shows the results of significant variables associated with sarcopenia in a regression model from backward stepwise selection. Across age, AWGS2019 sarcopenia prevalence was 6.9\% (21-59 years), $32.2 \%$ ( $\geq 60), 39.1 \%(\geq 65)$ and $53.4 \%(\geq 75)$. Participant characteristics and sarcopenia statuses are presented in Table 2. Factors associated with sarcopenia are shown in Table 3.

With AWGS2019, age, ethnicity, education level, housing type, living arrangement and marital status were associated with sarcopenia in univariate analysis $(p<.05)$. Age and marital status remained significant after multivariable analyses ( $p<.01)$. With EWGSOP2, age, gender and marital status were associated with sarcopenia after multivariable analyses $(p<.05)$.

\section{Health and Medical Conditions}

Diabetes, hypertension, high cholesterol and number of medical conditions were associated with sarcopenia in univariate analyses $(p<.01)$. Alcoholism was associated with AWGS2019 sarcopenia after multivariable analyses $(p<.01)$. 
MNA and GPAQ were associated with sarcopenia in univariate analyses $(p<.05)$. GPAQ remained significant after multivariable analyses in both AWGS2019 $(p<.01)$ and EWGSOP2 ( $p<.05)$.

\section{Anthropometry and Body Composition}

With univariate analysis, $\mathrm{BMI}$ and hip circumference were associated with sarcopenia ( $p<.001)$. BMD was associated with AWGS2019 sarcopenia ( $p<.01)$. After multivariable analyses, BMI remained significant $(p<.001)$, while waist circumference was associated with AWGS2019 sarcopenia $(p<.05)$.

\section{Cognitive Performance}

Global cognition was associated with sarcopenia in univariate analyses $(p<.001)$ and remained significant after multivariable analyses $(p<.05)$.

\section{Discussion}

Our study contributes to a growing Asian database for sarcopenia. It is the first population-based study to present reference values for muscle mass, strength, gait speed and sarcopenia prevalence across the age groups of community-dwelling Singaporean adults. Sarcopenia prevalence vary widely across studies. 5 Our estimated AWGS2014 prevalence was $18.0 \%$ ( $\geq 60$ years) and $24.1 \%(\geq 65)$, at the upper range (5.5$25.7 \%$ ) of those surveyed in the recent AWGS update.4 Other East Asian studies have reported similar prevalence of $27.8 \%$ (Korea)23 and 29.7\% (China),24 as well as much lower ones of $8.6 \%$ (Japan)25 and $6.8 \%$ (Taiwan). 26

Despite similarities in ethnicities and body size, the wide-ranging prevalences reported across Asian studies are attributable to the different assessment methods. Muscle mass assessed through bioimpedance analysis (BIA)23,24 is less consistent and reliable than DXA due to its dependence on hydration status, humidity and other assessment conditions. 4 There are yet insufficient studies to validate the use of BIA for specific Asian populations.1,4 The Lunar DXA machine26 may also give differing results from the Hologic machine used in this study.27 Inter-instrumental DXA measurements have low reliability and significant inter-manufacturer differences.27 Furthermore, handgrip strength assessed with the Smedley dynamometer25,26 has low agreement with the Jamar dynamometer used in this study.28 Recommended by the American Society of Hand Therapists, the Jamar is the most widely used and tested, has higher inter- and intra- individual reliability, and is considered the 'gold standard'.28

Sociodemographic differences among study populations (i.e., rural-dwellers, 23 suburban- $d$ wellers, 25 working farmers 26 and city community-dwellers24) could have further contributed to the heterogeneity of sarcopenia prevalence in Asian studies. Additionally, only $44.8 \%$ of Yuki et al.'s25 participants were aged $\geq 75$, compared to $54.8 \%$ in this study. Huang et al. 26 further acknowledged that their participants, mostly working farmers, had remarkable physical activity levels that probably protected them from sarcopenia. 
Our study sheds light on the ramifications of the AWGS guidelines that are promulgated and revised with the intent to reduce heterogeneity of prevalence and to standardize sarcopenia diagnosis. Sarcopenia prevalence in this study increased from 6.7\% (AWGS2014) to 13.6\% (AWGS2019) due to the revisions in diagnostic criteria. The proportions of our sample with low handgrip strength increased from $7.3 \%$ to $9.0 \%$, and slow gait speed from $4.1 \%$ to $24.0 \%$, the latter being most responsible for inflating sarcopenia prevalence. At the very least, this calls for caution when interpreting data according to the AWGS2014 and the current AWGS2019 criteria. To better refine diagnostic criteria, more normative data of handgrip strength, gait speed, and especially DXA-muscle mass based on young reference adult Asian populations are needed. Our population-derived cut-offs for HGS for men $(27.9 \mathrm{~kg})$ is identical to AWGS2019 $(28 \mathrm{~kg})$, and for women $(16.7 \mathrm{~kg})$ just a little lower than AWGS2019 $(18 \mathrm{~kg})$. For gait speed, our cut-off $(0.82 \mathrm{~m} / \mathrm{s})$ is lower than the revised AWGS2019 $(1.0 \mathrm{~m} / \mathrm{s})$, but close to the original AWGS2014 $(0.8 \mathrm{~m} / \mathrm{s})$. For DXAALMI, our cut-offs for men and women $(5.28$ and $3.69 \mathrm{~kg} / \mathrm{m} 2)$ are considerably lower than AWGS2019 $(7.0$ and $5.4 \mathrm{~kg} / \mathrm{m} 2)$. The latter cut-off values are placed at about the mean of this reference population for women, and roughly one SD below the mean for men, not two SD below the mean, which has the effect of inflating low muscle mass prevalence.

\section{Factors associated with sarcopenia}

Multivariable logistic regression using backward stepwise selection procedures revealed that age, gender, marital status, alcoholism, physical activity, BMI, waist circumference and global cognition were associated with sarcopenia. In sensitivity analyses, we also used forward selection which led to identical findings as backward selection for AWGS2019 analyses, but for EWGSOP2, it identified the same but two fewer risk factors. The full saturated models identified the same but one fewer risk factor for AWGS2019, and the same but three fewer risk factors for EWGSOP2. Forward selection has the drawback of suppressor effects, whereas leaving a large number of clearly insignificant factors in the model reduces the effects of potentially significant factors.

Older males were more likely to develop sarcopenia25,26,30 as age-related hormonal changes affect men more than women.30 Although age-associated decrease in sex hormones is a major contributor to loss of lean mass and increase in fat mass for both genders, fat promotes the conversion of androgens to estrogens, a process that exhibits anabolic effects only in women, 31 thereby attenuating the loss of lean mass and strength in women but not in men.

Higher BMI lowered the risk of sarcopenia.10,32 Overweight and obese individuals are better-nourished with diets higher in calories, proteins and nutrients, translating to better health outcomes than the underweight and malnourished.13,32 However, a larger waist circumference increased sarcopenia risk. Excess body fat exacerbates fat infiltration into muscle, decreasing muscle quality and physical performance.1,32 Increased abdominal and visceral fat stimulates the production of pro-inflammatory cytokines that perpetuate chronic and muscle inflammation, further contributing to muscle loss.30 Moreover, obese individuals are often less physically active, resulting in a gradual decrease in muscle 
mass and strength.32 Given the contrasting evidence, it is important to assess adiposity in addition to BMI.

Poorer global cognition increased sarcopenia risk. Gait and function require input from the executive functional, attentional, visuospatial and memory resources.33 Declining cognitive functions and brain structures affect gait and balance,34 and corroboratively, lower IQ, smaller brain volume and cortical thinning were associated with slower gait speed, suggesting that gait was influenced by brain health and neurocognition. 15 Indeed, a recent study reported the association between lower, but not upper, extremity muscle mass and cognitive impairment in persons with type 2 diabetes. 35 More studies can elucidate the relationship between specific cognitive domains and gait. Taken together, lower-extremity strength and cognition, both domains of intrinsic capacity,36 are important factors in sarcopenia prevention.

Low physical activity levels were associated with sarcopenia. Physical activity, although inconsistent in maintaining muscle mass and strength, lowers sarcopenia risk possibly through its effects on preserving physical function. 12

Interestingly, alcoholism was associated with AWGS2019 but not EWGSOP2 sarcopenia. This could be attributed to the different diagnostic criteria; poor physical function is confirmative of AWGS2019 sarcopenia, but merely indicative of severity in EWGSOP2.

Excessive alcohol intake propagates systemic inflammation, leading to mobility limitations and decreased physical performance.37 More specific measures of alcohol consumption could clarify our understanding of its effects on sarcopenia.

Notably, married adults had lower sarcopenia risk. Marital status is critical, especially in mid- to later-life, in regards to its protective effects on health and mortality through mutual care provision and reception.38

\section{Sarcopenia in younger adults}

Among younger and middle-aged adults (21-59 years), $32.4 \%$ have low muscle mass, $14.1 \%$ have probable sarcopenia, while $6.9 \%$ have sarcopenia, suggesting that sarcopenia was not exclusive to the older adults. Interventions to improve and maintain intrinsic capacity are needed well before old age so as to delay functional disability. Consistent with previous reports, our data showed that muscle mass and strength peak in early adulthood (31-40 years) before declining thereafter.39 Indeed, sarcopenia can develop from a multitude of factors secondary to ageing, 1 of which, physical inactivity, poor nutrition and obesity have been discussed previously.12,13,14 Identifying and implementing multi-domain lifestyle modifications over the adult lifespan and across life- stage transitions may be important to effectively prevent or delay the development of sarcopenia. Such multi-domain lifestyle interventions have been shown to reverse sarcopenia in community-dwelling older adults. 40

This study has several limitations. It presents cross-sectional data on the muscular health and function of Singaporeans and is subject to cohort effects. This may actually mean the younger generation of Singaporeans are at increased risk of sarcopenia. Age-related changes may not fully reflect the temporal 
changes across the lifetime, as well as the longitudinal trajectories of muscle mass and function, and the causal relationships between sarcopenia and the associated parameters. The participants were also relatively healthy, community-dwelling adults; therefore, the findings may not be generalisable to the institutionalised or disabled individuals.

\section{Conclusions And Implications}

This study presents new and much-needed reference data for appendicular lean mass index, handgrip strength, gait speed, and sarcopenia prevalence across age groups of community-dwelling adults in Singapore. Age, gender, marital status, alcoholism, physical activity, BMI, waist circumference and global cognition are associated with sarcopenia. Moreover, some younger adults are already at risk of sarcopenia. These findings add to Asian data on sarcopenia definition and suggest the important role of multi-domain lifestyle interventions to strengthen or maintain intrinsic capacity in younger and middleaged adults to reduce sarcopenia so as to delay functional disability in old age.

\section{Declarations}

\section{DISCLOSURE STATEMENT}

The authors declare no conflict of interest.

This research was supported as part of a core funding from the Ministry of Health of Singapore to GERI. The authors gratefully acknowledge the support of Dr. Lilian Chye, Sylvia Ngu, Aizuriah Mohamed Ali, Mary Ng Pei Ern, Chua Xing Ying and Shermaine Thein in this study.

\section{References}

1. Cruz-Jentoft A, Bahat G, Bauer J, Boirie Y, Bruyère 0 , Cederholm T et al. Sarcopenia: revised European consensus on definition and diagnosis. Age and Ageing. 2019;48(1):16-31. https://doi.org/10.1093/ageing/afy169.

2. Shafiee G, Keshtkar A, Soltani A, Ahadi Z, Larijani B, Heshmat R. Prevalence of sarcopenia in the world: a systematic review and meta- analysis of general population studies. Journal of Diabetes \& Metabolic Disorders. 2017;16(1). https://doi.org/10.1186/s40200-017-0302-x.

3. Cruz-Jentoft A, Baeyens J, Bauer J, Boirie Y, Cederholm T, Landi F et al. Sarcopenia: European consensus on definition and diagnosis: Report of the European Working Group on Sarcopenia in Older People. Age and Ageing. 2010;39(4):412-423. https://doi.org/10.1093/ageing/afq034.

4. Chen L, Liu L, Woo J, Assantachai P, Auyeung T, Bahyah K et al. Sarcopenia in Asia: Consensus Report of the Asian Working Group for Journal of the American Medical Directors Association. 2014;15(2):95-101. https://doi.org/10.1016/j.jamda.2013.11.025. 
5. Chen L, Lee W, Peng L, Liu L, Arai H, Akishita M. Recent Advances in Sarcopenia Research in Asia: 2016 Update From the Asian Working Group for Journal of the American Medical Directors Association. 2016;17(8):767.e1-767.e7. https://doi.org/10.1016/j.jamda.2016.05.016.

6. Chen L, Woo J, Assantachai P, Auyeung T, Chou M, lijima K et Asian Working Group for Sarcopenia: 2019 Consensus Update on Sarcopenia Diagnosis and Treatment. Journal of the American Medical Directors Association. 2020;21(3):300-307.e2. https://doi.org/10.1016/j.jamda.2019.12.012.

7. Tan L, Lim Z, Choe R, Seetharaman S, Merchant Screening for Frailty and Sarcopenia Among Older Persons in Medical Outpatient Clinics and its Associations With Healthcare Burden. Journal of the American Medical Directors Association. 2017;18(7):583-587.

https://doi.org/10.1016/j.jamda.2017.01.004.

8. Koh A, Wong J, Yew W, Chua S, Huang F, Leng $S$ et al. SARCOPENIA AND VASCULAR FUNCTION AMONG COMMUNITY ELDERLY. Journal of the American College of Cardiology. 2017;69(11):2051. https://doi.org/10.1016/S0735-1097(17)35440-2.

9. Fung F, Koh Y, Malhotra R, Ostbye T, Lee P, Shariff Ghazali S et al. Prevalence of and factors associated with sarcopenia among multi-ethnic ambulatory older Asians with type 2 diabetes mellitus in a primary care setting. BMC Geriatrics. 2019;19(1). https://doi.org/10.1186/s12877-019$1137-8$.

10. Tey S, Chew S, How C, Yalawar M, Baggs G, Chow W et al. Factors associated with muscle mass in community-dwelling older people in Singapore: Findings from the SHIELD study. PLOS ONE. 2019;14(10):e0223222. https://doi.org/10.1371/journal.pone.0223222.

11. Yang M, Hu X, Xie L, Zhang L, Zhou J, Lin J et al. SARC-F for sarcopenia screening in communitydwelling older adults. Medicine. 2018;97(30):e11726. https://dx.doi.org/10.1097\%2FMD.0000000000011726.

12. Mijnarends D, Koster A, Schols J, Meijers J, Halfens R, Gudnason V et al. Physical activity and incidence of sarcopenia: the population-based AGES-Reykjavik Study. Age and Ageing. 2016;45(5):614-620. https://doi.org/10.1093/ageing/afw090.

13. Cederholm T, Jensen G, Correia M, Gonzalez M, Fukushima R, Higashiguchi T et GLIM criteria for the diagnosis of malnutrition - A consensus report from the global clinical nutrition community. Journal of Cachexia, Sarcopenia and Muscle. 2019;10(1):207-217.

https://doi.org/10.1016/j.clnu.2018.08.002.

14. Kalinkovich A, Livshits G. Sarcopenic obesity or obese sarcopenia: A cross talk between ageassociated adipose tissue and skeletal muscle inflammation as a main mechanism of the pathogenesis. Ageing Research Reviews. 2017;35:200-221. https://doi.org/10.1016/j.arr.2016.09.008.

15. Rasmussen L, Caspi A, Ambler A, Broadbent J, Cohen H, d'Arbeloff T et al. Association of Neurocognitive and Physical Function With Gait Speed in Midlife. JAMA Network Open. 
2019;2(10):e1913123. https://doi.org/10.1001/jamanetworkopen.2019.13123.

16. De Spiegeleer A, Elewaut D, Van Den Noortgate N, Janssens Y, Debunne N, Van Langenhove S et al. Quorum sensing molecules as a novel microbial factor impacting muscle cells. Biochimica et Biophysica Acta (BBA) - Molecular Basis of Disease. 2020;1866(3):165646. https://doi.org/10.1016/j.bbadis.2019.165646.

17. Singapore Department of Statistics (DOS) [Internet]. 2020 [cited 5 May 2020]. Available from: https://www.singstat.gov.sg.

18. Hogg R, Tanis E, Zimmerman D. Probability and statistical inference. 9th ed. Pearson; 2015:202.

19. Kaiser M, Bauer J, Ramsch C, Uter W, Guigoz Y, Cederholm T et al. Validation of the Mini Nutritional Assessment short-form (MNA®-SF): A practical tool for identification of nutritional status. The Journal of Nutrition, Health and Aging. 2009;13(9):782-788. https://doi.org/10.1007/s12603-0090214-7.

20. Armstrong T, Bull F. Development of the World Health Organization Global Physical Activity Questionnaire (GPAQ). Journal of Public Health. 2006;14(2):66-70. https://doi.org/10.1007/s10389006-0024-x.

21. Stel V, Smit J, Pluijm S, Visser M, Deeg D, Lips P. Comparison of the LASA Physical Activity Questionnaire with a 7-day diary and pedometer. Journal of Clinical Epidemiology. 2004;57(3):252258. https://doi.org/10.1016/j.jclinepi.2003.07.008.

22. Collinson S, Fang S, Lim M, Feng L, Ng T. Normative Data for the Repeatable Battery for the Assessment of Neuropsychological Status in Elderly Chinese. Archives of Clinical Neuropsychology. 2014;29(5):442-455. https://doi.org/10.1093/arclin/acu023.

23. Jung $H$, Jang I, Lee $Y$, Lee $C$, Cho E, Kang W et Prevalence of Frailty and Aging-Related Health Conditions in Older Koreans in Rural Communities: a Cross-Sectional Analysis of the Aging Study of Pyeongchang Rural Area. Journal of Korean Medical Science. 2016;31(3):345. https://doi.org/10.3346/jkms.2016.31.3.345.

24. Wang Y, Wang Y, Zhan J, Tang Z, He J, Tan P et al. Sarco-Osteoporosis: Prevalence and Association with Frailty in Chinese Community-Dwelling Older Adults. International Journal of Endocrinology. 2015;2015:1-8. https://doi.org/10.1155/2015/482940.

25. Yuki A, Ando F, Otsuka R, Matsui Y, Harada A, Shimokata H. Epidemiology of sarcopenia in elderly Japanese. The Journal of Physical Fitness and Sports Medicine. 2015;4(1):111-115. https://doi.org/10.7600/jpfsm.4.111.

26. Huang C, Hwang A, Liu L, Lee W, Chen L, Peng L et al. Association of Dynapenia, Sarcopenia, and Cognitive Impairment Among Community-Dwelling Older Rejuvenation Research. 2016;19(1):71-78. https://doi.org/10.1089/rej.2015.1710. 
27. Aasen G, Fagertun H, Halse Body composition analysis by dual X-ray absorptiometry: in vivo and in vitro comparison of three different fan-beam instruments. Scandinavian Journal of Clinical and Laboratory Investigation. 2006;66(8):659-666. https://doi.org/10.1080/00365510600898214.

28. Sousa-Santos A, Amaral T. Differences in handgrip strength protocols to identify sarcopenia and frailty - a systematic review. BMC Geriatrics. 2017;17(1). https://doi.org/10.1186/s12877-017-0625-y.

29. Cruz-Jentoft A, Landi F, Schneider S, Zuniga C, Arai H, Boirie $Y$ et al. Prevalence of and interventions for sarcopenia in ageing adults: a systematic review. Report of the International Sarcopenia Initiative (EWGSOP and IWGS). Age and Ageing. 2014;43(6):748-759. https://doi.org/10.1093/ageing/afu115.

30. Ryu M, Jo J, Lee Y, Chung Y, Kim K, Baek W. Association of physical activity with sarcopenia and sarcopenic obesity in community-dwelling older adults: the Fourth Korea National Health and Nutrition Examination Survey. Age and Ageing. 2013;42(6):734-740. https://doi.org/10.1093/ageing/aft063.

31. Flöter A, Nathorst-böös J, Carlström K, Ohlsson C, Ringertz H, von Schoultz B. Effects of combined estrogen/testosterone therapy on bone and body composition in oophorectomized women. Gynecological Endocrinology. 2005;20(3):155-160. https://doi.org/10.1080/09513590400021193.

32. Cheng $Q$, Zhu X, Zhang X, Li H, Du Y, Hong W et al. A cross-sectional study of loss of muscle mass corresponding to sarcopenia in healthy Chinese men and women: reference values, prevalence, and association with bone mass. Journal of Bone and Mineral Metabolism. 2013;32(1):78-88. https://doi.org/10.1007/s00774-013-0468-3.

33. Amboni, , Barone, P., \& Hausdorff, J. (2013). Cognitive contributions to gait and falls: Evidence and implications. Movement Disorders, 28(11), 1520-1533. https://doi.org/10.1002/mds.25674.

34. Herter T, Scott S, Dukelow Systematic changes in position sense accompany normal aging across adulthood. Journal of NeuroEngineering and Rehabilitation. 2014;11(1):43. https://doi.org/10.1186/1743-0003-11-43.

35. Low S, Ng T, Lim C, Moh A, Ang S, Wang J et al. Association between Lower Extremity Skeletal Muscle Mass and Impaired Cognitive Function in Type 2 Diabetes. Scientific Reports. 2020;10(1). https://doi.org/10.1038/s41598-020-59914-3.

36. Cesari M, Araujo de Carvalho I, Amuthavalli Thiyagarajan J, Cooper C, Martin F, Reginster J et al. Evidence for the Domains Supporting the Construct of Intrinsic Capacity. The Journals of Gerontology: Series A. 2018;73(12):1653-1660. https://doi.org/10.1093/gerona/gly011.

37. Cawthon P, Fink H, Barrett-Connor E, Cauley J, Dam T, Lewis C et al. Alcohol Use, Physical Performance, and Functional Limitations in Older Men. Journal of the American Geriatrics Society. 2007;55(2):212-220. https://doi.org/10.1111/j.1532-5415.2007.01062.x.

38. Robards J, Evandrou M, Falkingham J, Vlachantoni A. Marital status, health and mortality. Maturitas. 2012;73(4):295-299. https://dx.doi.org/10.1016\%2Fj.maturitas.2012.08.007. 
39. Volpi E, Nazemi R, Fujita S. Muscle tissue changes with aging. Current Opinion in Clinical Nutrition and Metabolic Care. 2004;7(4):405-410. https://doi.org/10.1097/01.mco.0000134362.76653.b2.

40. Lu Y, Niti M, Yap K, Tan C, Zin Nyunt M, Feng L et Assessment of Sarcopenia Among CommunityDwelling At-Risk Frail Adults Aged 65 Years and Older Who Received Multidomain Lifestyle Interventions. JAMA Network Open. 2019;2(10):e1913346.

https://doi.org/10.1001/jamanetworkopen.2019.13346.

\section{Tables}

\begin{tabular}{|c|c|c|c|c|c|c|c|c|c|c|c|}
\hline \multicolumn{2}{|c|}{ Age Group (y) } & $21-30$ & $31-40$ & $41-50$ & $51-60$ & $61-65$ & $66-70$ & $71-75$ & $76-80$ & $\geq 81$ & Overall \\
\hline \multicolumn{12}{|c|}{ AWGS2014 Sarcopenia } \\
\hline Confirmed & Female & $\begin{array}{c}0 \\
(0) \\
0 \\
(0)\end{array}$ & $\begin{array}{c}0 \\
(0) \\
1 \\
(2.9)\end{array}$ & $\begin{array}{c}0 \\
(0) \\
1 \\
(2.6)\end{array}$ & $\begin{array}{c}1 \\
(4.5) \\
2 \\
(5.4)\end{array}$ & $\begin{array}{c}3 \\
(10.3) \\
1 \\
(3.2)\end{array}$ & $\begin{array}{c}4 \\
(16.7) \\
3 \\
(8.6)\end{array}$ & $\begin{array}{c}7 \\
(24.1) \\
8 \\
(27.6)\end{array}$ & $\begin{array}{c}8 \\
(30.8) \\
8 \\
(23.5)\end{array}$ & $\begin{array}{c}13 \\
(56.5) \\
23 \\
(62.2)\end{array}$ & $\begin{array}{c}36 \\
(15.9) \\
47 \\
(15.2)\end{array}$ \\
\hline \multicolumn{12}{|c|}{ AWGS2019 Sarcopenia } \\
\hline \multirow{2}{*}{ Probable } & Male & $\begin{array}{c}3 \\
(10.7)\end{array}$ & $\begin{array}{c}6 \\
(23.1)\end{array}$ & $\begin{array}{c}4 \\
(20.0)\end{array}$ & $\begin{array}{c}4 \\
(18.2)\end{array}$ & $\begin{array}{c}1 \\
(3.4)\end{array}$ & $\begin{array}{c}2 \\
(8.3)\end{array}$ & $\begin{array}{c}7 \\
(24.1)\end{array}$ & $\begin{array}{c}3 \\
(11.5)\end{array}$ & $\begin{array}{c}2 \\
(8.7)\end{array}$ & $\begin{array}{c}32 \\
(14.1)\end{array}$ \\
\hline & Female & $\begin{array}{c}2 \\
(6.3)\end{array}$ & $\begin{array}{c}4 \\
(11.4)\end{array}$ & $\begin{array}{c}4 \\
(10.3)\end{array}$ & $\begin{array}{c}5 \\
(13.5)\end{array}$ & $\begin{array}{c}2 \\
(6.5)\end{array}$ & $\begin{array}{c}7 \\
(20.0)\end{array}$ & $\begin{array}{c}5 \\
(17.2)\end{array}$ & $\begin{array}{c}13 \\
(38.2)\end{array}$ & $\begin{array}{c}8 \\
(21.6)\end{array}$ & $\begin{array}{c}50 \\
(16.2)\end{array}$ \\
\hline \multirow{2}{*}{ Confirmed } & Male & $\begin{array}{c}0 \\
(0)\end{array}$ & $\begin{array}{c}0 \\
(0)\end{array}$ & $\begin{array}{c}0 \\
(0)\end{array}$ & $\begin{array}{c}2 \\
(9.1)\end{array}$ & $\begin{array}{c}5 \\
(17.2)\end{array}$ & $\begin{array}{c}5 \\
(20.8)\end{array}$ & $\begin{array}{c}5 \\
(17.2)\end{array}$ & $\begin{array}{c}7 \\
(26.9)\end{array}$ & $\begin{array}{c}7 \\
(30.4)\end{array}$ & $\begin{array}{c}31 \\
(13.7)\end{array}$ \\
\hline & Female & $\begin{array}{c}3 \\
(9.4)\end{array}$ & $\begin{array}{c}4 \\
(11.4)\end{array}$ & $\begin{array}{c}1 \\
(2.6)\end{array}$ & $\begin{array}{c}2 \\
(5.4)\end{array}$ & $\begin{array}{c}5 \\
(16.1)\end{array}$ & $\begin{array}{c}6 \\
(17.1)\end{array}$ & $\begin{array}{c}11 \\
(37.9)\end{array}$ & $\begin{array}{c}8 \\
(23.5)\end{array}$ & $\begin{array}{c}12 \\
(32.4)\end{array}$ & $\begin{array}{c}52 \\
(16.8)\end{array}$ \\
\hline \multirow{2}{*}{ Severe } & Male & $\begin{array}{c}1 \\
(3.6)\end{array}$ & $\begin{array}{c}0 \\
(0)\end{array}$ & $\begin{array}{c}0 \\
(0)\end{array}$ & $\begin{array}{c}1 \\
(4.5)\end{array}$ & $\begin{array}{c}2 \\
(6.9)\end{array}$ & $\begin{array}{c}2 \\
(8.3)\end{array}$ & $\begin{array}{c}6 \\
(20.7)\end{array}$ & $\begin{array}{c}7 \\
(26.9)\end{array}$ & $\begin{array}{c}10 \\
(43.5)\end{array}$ & $\begin{array}{c}29 \\
(12.8)\end{array}$ \\
\hline & Female & $\begin{array}{c}0 \\
(0)\end{array}$ & $\begin{array}{c}0 \\
(0)\end{array}$ & $\begin{array}{c}0 \\
(0)\end{array}$ & $\begin{array}{c}1 \\
(2.7)\end{array}$ & $\begin{array}{c}1 \\
(3.2)\end{array}$ & $\begin{array}{c}1 \\
(2.9)\end{array}$ & $\begin{array}{c}2 \\
(6.9)\end{array}$ & $\begin{array}{c}5 \\
(14.7)\end{array}$ & $\begin{array}{c}15 \\
(40.5)\end{array}$ & $\begin{array}{c}25 \\
(8.1) \\
\end{array}$ \\
\hline \multicolumn{12}{|c|}{ EWGSOP2 Sarcopenia } \\
\hline \multirow{2}{*}{ Probable } & Male & $\begin{array}{c}1 \\
(3.6)\end{array}$ & $\begin{array}{c}0 \\
(0)\end{array}$ & $\begin{array}{c}0 \\
(0)\end{array}$ & $\begin{array}{c}0 \\
(0)\end{array}$ & $\begin{array}{c}0 \\
(0)\end{array}$ & $\begin{array}{c}2 \\
(8.3)\end{array}$ & $\begin{array}{c}3 \\
(10.3)\end{array}$ & $\begin{array}{c}1 \\
(3.8)\end{array}$ & $\begin{array}{c}1 \\
(4.3)\end{array}$ & $\begin{array}{c}8 \\
(3.5)\end{array}$ \\
\hline & Female & $\begin{array}{c}0 \\
(0)\end{array}$ & $\begin{array}{c}0 \\
(0)\end{array}$ & $\begin{array}{c}0 \\
(0)\end{array}$ & $\begin{array}{c}1 \\
(2.7)\end{array}$ & $\begin{array}{c}1 \\
(3.2)\end{array}$ & $\begin{array}{c}2 \\
(5.7)\end{array}$ & $\begin{array}{c}0 \\
(0)\end{array}$ & $\begin{array}{c}5 \\
(14.7)\end{array}$ & $\begin{array}{c}3 \\
(8.1)\end{array}$ & $\begin{array}{c}12 \\
(3.9)\end{array}$ \\
\hline \multirow[b]{2}{*}{ Confirmed } & Male & $\begin{array}{c}0 \\
(0)\end{array}$ & $\begin{array}{c}0 \\
(0)\end{array}$ & $\begin{array}{c}0 \\
(0)\end{array}$ & $\begin{array}{c}1 \\
(4.5)\end{array}$ & $\begin{array}{c}2 \\
(6.9)\end{array}$ & $\begin{array}{c}2 \\
(8.3)\end{array}$ & $\begin{array}{c}2 \\
(6.9)\end{array}$ & 3 & 3 & $\begin{array}{c}13 \\
(5.7)\end{array}$ \\
\hline & Female & $\begin{array}{c}\text { (v) } \\
0 \\
(0)\end{array}$ & $\begin{array}{c}1 \\
(2.9)\end{array}$ & $\begin{array}{c}0 \\
(0)\end{array}$ & $\begin{array}{c}1 \\
(2.7)\end{array}$ & $\begin{array}{c}0 \\
(0)\end{array}$ & $\begin{array}{c}2 \\
(5.7)\end{array}$ & $\begin{array}{c}4 \\
(13.8)\end{array}$ & $\begin{array}{c}1 \\
(2.9)\end{array}$ & $\begin{array}{c}3 \\
(8.1)\end{array}$ & $\begin{array}{c}12 \\
(3.9)\end{array}$ \\
\hline \multirow[b]{2}{*}{ Severe } & Male & $\begin{array}{c}1 \\
1 \\
(3.6)\end{array}$ & $\begin{array}{c}(2.9) \\
0 \\
(0)\end{array}$ & $\begin{array}{c}(0) \\
0 \\
(0)\end{array}$ & $\begin{array}{c}1 \\
1 \\
(4.5)\end{array}$ & $\begin{array}{c}2 \\
(6.9)\end{array}$ & $\begin{array}{c}(3.7) \\
2 \\
(8.3)\end{array}$ & $\begin{array}{c}(13.8) \\
6 \\
(20.7)\end{array}$ & $\begin{array}{c}(2.9) \\
7 \\
(26.9)\end{array}$ & $\begin{array}{c}(8.1) \\
(43.5)\end{array}$ & $\begin{array}{c}29 \\
(12.8)\end{array}$ \\
\hline & Female & $\begin{array}{c}0 \\
0 \\
(0)\end{array}$ & $\begin{array}{c}0 \\
(0)\end{array}$ & $\begin{array}{c}0 \\
(0)\end{array}$ & $\begin{array}{c}1 \\
(2.7)\end{array}$ & $\begin{array}{c}1 \\
(3.2)\end{array}$ & $\begin{array}{c}1 \\
(2.9)\end{array}$ & $\begin{array}{c}2 \\
(6.9)\end{array}$ & $\begin{array}{c}5 \\
(14.7)\end{array}$ & $\begin{array}{c}15 \\
(40.5)\end{array}$ & $\begin{array}{c}25 \\
(8.1)\end{array}$ \\
\hline
\end{tabular}

Values are presented as number (\%) 
Table 2. Participant characteristics and sarcopenia status according to AWGS2019.

\begin{tabular}{|c|c|c|c|c|c|}
\hline Characteristics & $\begin{array}{l}\text { Total } \\
n=536\end{array}$ & $\begin{array}{l}\text { No Sarcopenia } \\
n=317\end{array}$ & $\begin{array}{l}\text { Probable } \\
n=82\end{array}$ & $\begin{array}{l}\text { Confirmed } \\
n=83\end{array}$ & $\begin{array}{l}\text { Severe } \\
n=54\end{array}$ \\
\hline Age (y) & $58.5(18.8)$ & $51.5(17.2)$ & $62.4(18.6)$ & $69.6(14.5)$ & $76.7(10.3)$ \\
\hline $21-40$ & $121(22.6)$ & $98(30.9)$ & $15(18.3)$ & $7(8.4)$ & $1(1.9)$ \\
\hline $41-60$ & $118(22.0)$ & $94(29.7)$ & $17(20.7)$ & $5(6.0)$ & $2(3.7)$ \\
\hline $61-80$ & $237(44.2)$ & $119(37.5)$ & $40(48.8)$ & $52(62.7)$ & $26(48.1)$ \\
\hline$\geq 81$ & $60(11.2)$ & $6(1.9)$ & $10(12.2)$ & $19(22.9)$ & $25(46.3)$ \\
\hline \multicolumn{6}{|l|}{ Gender } \\
\hline Male & $227(42.4)$ & $135(42.6)$ & $32(39.0)$ & $31(37.3)$ & $29(53.7)$ \\
\hline Female & $309(57.6)$ & $182(57.4)$ & $50(61.0)$ & $52(62.7)$ & $25(46.3)$ \\
\hline \multicolumn{6}{|l|}{ Ethnicity } \\
\hline Chinese & $438(81.7)$ & $259(81.7)$ & $57(69.5)$ & $76(91.6)$ & $46(85.2)$ \\
\hline Malay & $46(8.6)$ & $33(10.4)$ & $11(13.4)$ & $1(1.2)$ & $1(1.9)$ \\
\hline Indian & $37(6.9)$ & $18(5.7)$ & $9(11.0)$ & $5(6.0)$ & $5(9.3)$ \\
\hline Others & $15(2.8)$ & $7(2.2)$ & $5(6.1)$ & $1(1.2)$ & $2(3.7)$ \\
\hline \multicolumn{6}{|l|}{ Highest Qualification } \\
\hline$\leq$ Primary & $173(32.3)$ & $62(19.6)$ & $39(47.6)$ & $42(50.6)$ & $30(55.6)$ \\
\hline Secondary & $165(30.8)$ & $110(34.7)$ & $16(19.5)$ & $26(31.3)$ & $13(24.1)$ \\
\hline Tertiary & $115(21.5)$ & $84(26.5)$ & 15 (18.3) & $11(13.3)$ & $5(9.3)$ \\
\hline$\geq$ Degree & $83(15.5)$ & $61(19.2)$ & $12(14.6)$ & $4(4.8)$ & $6(11.1)$ \\
\hline \multicolumn{6}{|l|}{ Years of Education (y) } \\
\hline$\leq 6$ & $169(31.5)$ & $59(18.6)$ & $38(46.3)$ & $42(50.6)$ & $30(55.6)$ \\
\hline $7-12$ & $201(37.5)$ & $134(42.3)$ & $23(28.0)$ & $27(32.5)$ & $17(31.5)$ \\
\hline$\geq 13$ & $166(31.0)$ & $124(39.1)$ & $21(25.6)$ & $14(16.9)$ & $7(13.0)$ \\
\hline \multicolumn{6}{|l|}{ Housing Type } \\
\hline $1-2$ rooms & $63(11.8)$ & $21(6.6)$ & $11(13.4)$ & 15 (18.1) & $16(29.6)$ \\
\hline 3 rooms & $111(20.7)$ & $64(20.2)$ & $12(14.6)$ & $26(31.3)$ & $9(16.7)$ \\
\hline 4-5 rooms & $316(59.0)$ & $201(63.4)$ & $53(64.6)$ & $37(44.6)$ & $25(46.3)$ \\
\hline High-end Public/Private & $46(8.6)$ & $31(9.8)$ & $6(7.3)$ & $5(6.0)$ & $4(7.4)$ \\
\hline \multicolumn{6}{|c|}{ Living Arrangement $(n=487)$} \\
\hline Alone & $42(8.6)$ & $19(6.8)$ & $4(5.3)$ & $11(13.9)$ & $8(15.1)$ \\
\hline Not Alone & $445(91.4)$ & $261(93.2)$ & $71(94.7)$ & $68(86.1)$ & $45(84.9)$ \\
\hline \multicolumn{6}{|l|}{ Marital Status $(n=509)$} \\
\hline Married & $348(68.4)$ & $215(71.9)$ & $53(67.9)$ & $49(62.0)$ & $31(58.5)$ \\
\hline Single & $75(14.7)$ & $61(20.4)$ & $6(7.7)$ & $6(7.6)$ & $2(3.8)$ \\
\hline Divorced/Separated & $17(3.3)$ & $8(2.7)$ & $2(2.6)$ & $5(6.3)$ & $2(3.8)$ \\
\hline Widowed & $69(13.6)$ & $15(5.0)$ & $17(21.8)$ & $19(24.1)$ & $18(34.0)$ \\
\hline \multicolumn{6}{|l|}{ Medical Conditions } \\
\hline No Known Conditions & $236(44.0)$ & $174(54.9)$ & $28(34.1)$ & $24(28.9)$ & $10(18.5)$ \\
\hline Diabetes & $80(14.9)$ & $28(8.8)$ & $16(19.5)$ & $17(20.5)$ & $19(35.2)$ \\
\hline Hypertension & $196(36.6)$ & $80(25.2)$ & $38(46.3)$ & $44(53.0)$ & $34(63.0)$ \\
\hline High Cholesterol & $202(37.7)$ & $85(26.8)$ & $46(56.1)$ & $41(49.4)$ & $30(55.6)$ \\
\hline Others & $33(6.2)$ & $18(5.7)$ & $4(4.9)$ & $6(7.2)$ & $5(9.3)$ \\
\hline $1-3$ & $258(48.1)$ & $132(41.6)$ & $45(54.9)$ & $48(57.8)$ & $33(61.1)$ \\
\hline$\geq 4$ & $42(7.8)$ & $11(3.5)$ & $9(11.0)$ & $11(13.3)$ & $11(20.4)$ \\
\hline \multicolumn{6}{|l|}{ Smoking and Drinking } \\
\hline Smokers/Ex-smokers & $115(21.5)$ & $66(20.8)$ & $18(22.0)$ & $16(19.2)$ & $15(27.8)$ \\
\hline Alcoholics/Ex-alcoholics & $46(8.6)$ & $25(7.9)$ & $4(4.9)$ & $10(12.0)$ & $7(13.0)$ \\
\hline Smoke and Drink & $25(4.7)$ & $12(3.8)$ & $3(3.7)$ & $4(4.8)$ & $6(11.1)$ \\
\hline
\end{tabular}

Values are presented as mean (SD) or number (\%) 
Table 3. Factors associated with sarcopenia using logistic regression.

\begin{tabular}{|c|c|c|c|c|}
\hline & \multicolumn{2}{|c|}{ Univariate } & \multicolumn{2}{|c|}{ Multivariable } \\
\hline & AWGS2019 & EWGSOP2 & AWGS2019 & EWGSOP2 \\
\hline Characteristics & Odds Ratio (95\% CI) & Odds Ratio $(95 \% \mathrm{CI})$ & Odds Ratio $(95 \% \mathrm{CI})$ & Odds Ratio $(95 \% \mathrm{CI})$ \\
\hline Age, years & $1.08(1.06-1.10)^{* * *}$ & $1.10(1.08-1.13)^{* * *}$ & $1.07(1.04-1.09)^{* * * *}$ & $1.08(1.04-1.12)^{* * * *}$ \\
\hline Female & 1 & 1 & - & 1 \\
\hline Male & $1.08(0.73-1.60)$ & $1.67(1.03-2.70)^{*}$ & - & $2.20(1.15-4.19)^{*}$ \\
\hline \multicolumn{5}{|l|}{ Ethnicity } \\
\hline Non-Chinese & 1 & 1 & - & - \\
\hline Chinese & $2.14(1.19-3.85)^{*}$ & $1.88(0.91-3.91)$ & - & - \\
\hline \multicolumn{5}{|l|}{ Education Level } \\
\hline Tertiary and above & 1 & 1 & - & - \\
\hline Secondary and below & $3.24(2.02-5.18)^{* * *}$ & $3.13(1.71-5.74)^{* * *}$ & - & - \\
\hline \multicolumn{5}{|l|}{ Housing Type } \\
\hline 4-Room and above & 1 & 1 & - & - \\
\hline 3-Room and below & $2.51(1.68-3.74)^{* * *}$ & $1.82(1.12-2.96)^{*}$ & - & - \\
\hline \multicolumn{5}{|l|}{ Living Arrangement } \\
\hline Not Alone & 1 & 1 & - & - \\
\hline Alone & $2.43(1.28-4.62)^{* * *}$ & $1.76(0.83-3.76)$ & - & - \\
\hline \multicolumn{5}{|l|}{ Marital Status } \\
\hline Not Married & 1 & 1 & 1 & 1 \\
\hline Married & $0.63(0.41-0.95)^{*}$ & $0.64(0.39-1.05)$ & $0.41(0.23-0.73)^{* *}$ & $0.48(0.25-0.94)^{*}$ \\
\hline \multicolumn{5}{|l|}{ Diabetes } \\
\hline No & 1 & 1 & - & - \\
\hline Yes & $2.88(1.76-4.71)^{* * * *}$ & $3.13(1.79-5.44)^{* * *}$ & - & - \\
\hline \multicolumn{5}{|l|}{ Hypertension } \\
\hline No & 1 & 1 & - & - \\
\hline Yes & $3.15(2.11-4.70)^{* * *}$ & $3.23(1.98-5.29)^{* * *}$ & - & - \\
\hline \multicolumn{5}{|l|}{ High Cholesterol } \\
\hline No & 1 & 1 & - & - \\
\hline Yes & $2.20(1.48-3.27)^{* * * *}$ & $1.98(1.23-3.21)^{* *}$ & - & - \\
\hline No. of Medical Conditions & $1.56(1.36-1.80)^{* * *}$ & $1.45(1.24-1.70)^{* * * *}$ & - & - \\
\hline \multicolumn{5}{|l|}{ Smoker/Ex-smoker } \\
\hline No & 1 & 1 & - & - \\
\hline Yes & $1.10(0.69-1.75)$ & $1.19(0.68-2.09)$ & - & - \\
\hline \multicolumn{5}{|l|}{ Alcoholic/Ex-alcoholic } \\
\hline No & 1 & 1 & 1 & - \\
\hline Yes & $1.81(0.96-3.40)$ & $1.24(0.56-2.77)$ & $4.04(1.59-10.22)^{* * *}$ & - \\
\hline Self-rated Health & $1.05(0.82-1.35)$ & $1.32(0.98-1.79)$ & - & - \\
\hline MNA Score & $0.76(0.67-0.87)^{* * *}$ & $0.80(0.68-0.92)^{* * *}$ & - & - \\
\hline \multicolumn{5}{|l|}{ Physical Activity } \\
\hline GPAQ, MET h/week & $0.99(0.99-1.00)^{* * *}$ & $0.99(0.99-1.00)^{* * *}$ & $0.99(0.99-1.00)^{* *}$ & $0.99(0.99-1.00)^{*}$ \\
\hline LAPAQ, MET h/week & $1.00(0.99-1.00)$ & $1.00(0.99-1.00)$ & - & - \\
\hline $\mathrm{BMI}, \mathrm{kg} / \mathrm{m}^{2}$ & $0.82(0.77-0.87)^{* * *}$ & $0.83(0.77-0.90)^{* * *}$ & $0.66(0.58-0.77)^{* * * *}$ & $0.78(0.71-0.86)^{* * * *}$ \\
\hline Waist Circumference, $\mathrm{cm}$ & $0.98(0.97-1.00)$ & $0.99(0.97-1.01)$ & $1.05(1.00-1.11)^{*}$ & - \\
\hline Hip Circumference, cm & $0.92(0.89-0.95)^{* * *}$ & $0.92(0.88-0.95)^{* * *}$ & - & - \\
\hline RBANS Total Score & $0.98(0.97-0.98)^{* * *}$ & $0.98(0.97-0.98)^{* * * *}$ & $0.99(0.98-1.00)^{*}$ & $0.99(0.98-1.00)^{*}$ \\
\hline BMD (w/o head), g/cm² & $0.06(0.01-0.33)^{* *}$ & $0.34(0.05-2.35)$ & - & - \\
\hline
\end{tabular}

\section{Figures}




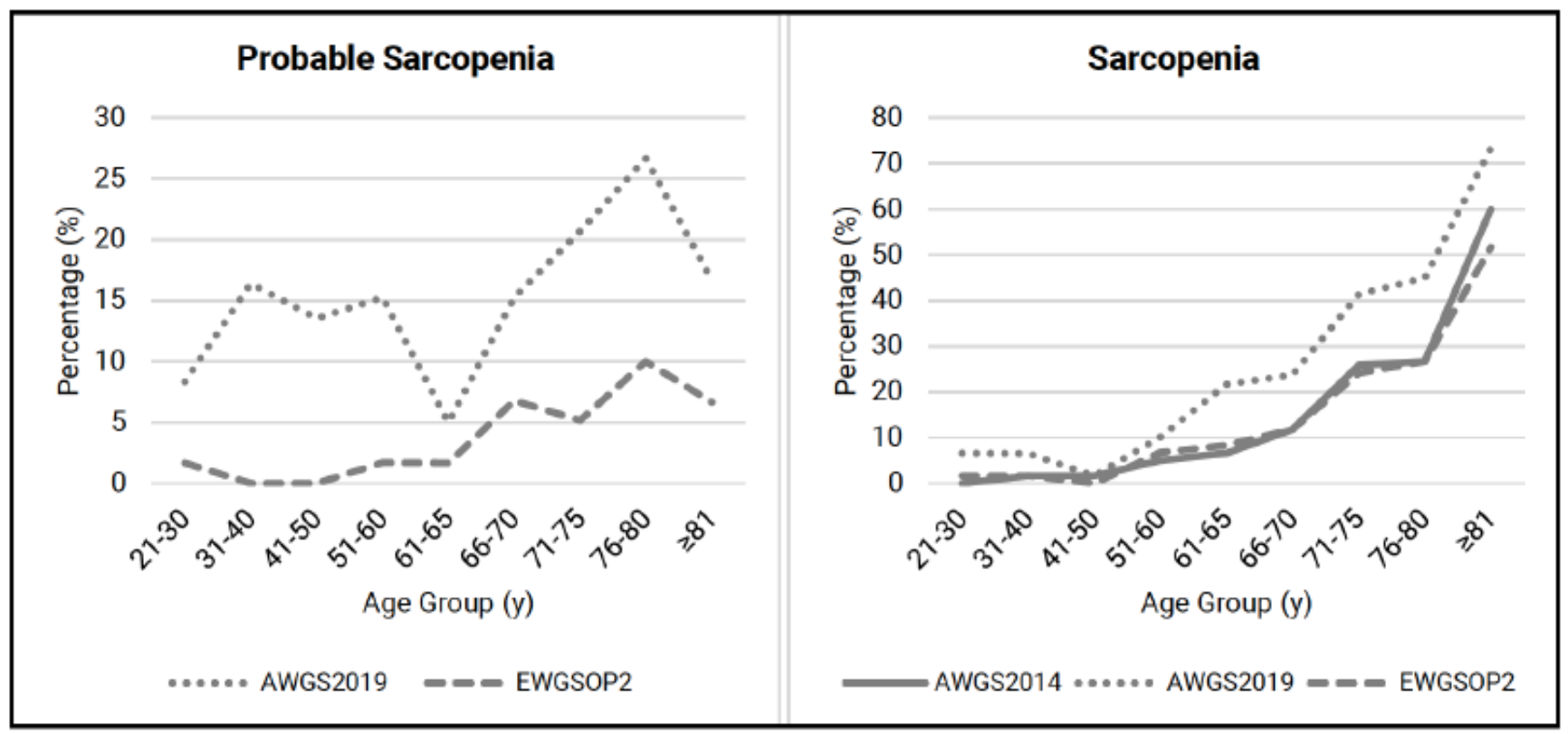

Figure 1. Comparisons among the diagnostic criteria; AWGS2014, AWGS2019 and EWGSOP2.

\section{Figure 1}

\section{Supplementary Files}

This is a list of supplementary files associated with this preprint. Click to download.

- SupplementalTables.pdf 